\title{
Linking diverse nutrient patterns to different water masses within anticyclonic eddies in the upwelling system off Peru
}

\author{
Yonss Saranga José, Heiner Dietze, and Andreas Oschlies \\ GEOMAR Helmholtz Centre for Ocean Research Kiel, Kiel, Germany \\ Correspondence to: Yonss Saranga José (yjose@geomar.de)
}

Received: 24 May 2016 - Discussion started: 10 June 2016

Revised: 9 February 2017 - Accepted: 21 February 2017 - Published: 20 March 2017

\begin{abstract}
Ocean eddies can both trigger mixing (during their formation and decay) and effectively shield water encompassed from being exchanged with ambient water (throughout their lifetimes). These antagonistic effects of eddies complicate the interpretation of synoptic snapshots typically obtained by ship-based oceanographic measurement campaigns. Here we use a coupled physical-biogeochemical model to explore biogeochemical dynamics within anticyclonic eddies in the eastern tropical South Pacific Ocean. The goal is to understand the diverse biogeochemical patterns that have been observed at the subsurface layers of the anticyclonic eddies in this region. Our model results suggest that the diverse subsurface nutrient patterns within eddies are associated with the presence of water masses of different origins at different depths.
\end{abstract}

\section{Introduction}

Satellite-based measurements have revealed strong correlations between sea surface height and ocean colour (e.g. Cipollini et al., 2001). Most of these correlations are related to non-linear mesoscale eddies which shape a distinct biogeochemical environment that differs from ambient surrounding waters (e.g. Chelton et al., 2011). Processes that were proposed to shape distinctly differing environments in energetic mesoscale eddies include eddy vertical transport, such as pumping during the formation and intensification (decay) of cyclonic (anticyclonic) eddies (e.g. Jenkins, 1988; Falkowski et al., 1991) and eddy/wind effects driving upwelling in anticyclonic eddies (e.g. Martin and Richards, 2001). Common to these processes is that they have been proposed to enhance near-surface vertical transport and thus in- crease the availability of essential nutrients in the sunlit surface ocean (Mahadevan and Archer, 2000; Lévy et al., 2001). Another trait of eddies, somewhat antagonistic, is their role in lateral transport processes. Eddies can enclose water parcels and effectively shield them from being mixed with ambient waters for months (e.g. Dietze et al., 2009). This can render the interpretation of synoptic snapshots, such those as obtained by ship-based oceanographic measurement campaigns, problematic because local conditions may well be the result of processes hosted hundreds of miles away in the past rather than being effected locally and contemporarily which, in turn, can obscure causal relationships.

This study sets out to investigate if and to what extent standing stocks of biogeochemically relevant species are decoupled from local contemporary processes in eddies in the eastern tropical South Pacific (ETSP). The region is known for oxygen-deprived waters at intermediate depth (Chavez et al., 2008) that host anoxic biogeochemical cycling of organic matter such as denitrification (Codispoti and Christensen, 1985; Farías et al., 2009) and anaerobic ammonium oxidation (anammox) (Hamersley et al., 2007; Lam et al., 2009) - both of which are key to setting the global inventory of bioavailable nitrogen that is essential for phytoplankton growth. A recent survey in the ETSP oxygen minimum zone (OMZ) revealed strong correlations between mesoscale eddies and subsurface nutrients (Altabet et al., 2012; Stramma et al., 2013). Specifically, two anticyclonic eddies were identified which were associated with both low and high nitrate concentrations in their centres. According to the authors of the earlier studies, the nitrate deficit in the low-nitrate eddy was caused by local denitrification and/or dissimilatory nitrate reduction to ammonia (DNRA). As for the high-nitrate eddy, the authors speculated that the nutrient anomaly was 
related to the initial concentration at the time and place of the eddy formation. Here, we aim at a more comprehensive analysis of eddies in the region, which explicitly considers their life histories. To this end we will apply a coupled, eddy-resolving ocean circulation biogeochemical model of the ETSP. Eddies similar to those observed by Altabet et al. (2012) and Stramma et al. (2013) will be analysed. The focus is on nutrient dynamics and water mass properties within the eddies throughout their lifetimes.

\section{Methods}

We employ the Regional Oceanic Model System (ROMS, Shchepetkin and McWilliams, 2005) to simulate the dynamics of the ETSP ocean. This free-surface and terrainfollowing vertical coordinates model (Shchepetkin and McWilliams, 2005) allows the allocation of high resolution in the surface and coastal regions, which are crucial for the biogeochemical processes. The ROMS model is coupled with BioEBUS (Biogeochemical model for the Eastern Boundary Upwelling Systems) to simulate the first trophic levels of the food web and the biogeochemical dynamics. Detailed descriptions of the BioEBUS is presented in Gutknecht et al. (2013) and in the Supplement of this study (Sect. 1). The first trophic levels of the BioEBUS model consist of small (flagellated and microzooplankton) and large (diatoms and mesozooplankton) organisms. The flagellates differ from the diatoms in their adaptation to low nutrients and stratified conditions, as well as their better assimilation efficiency for nutrients. The BioEBUS model is a nitrogen-based model that accounts for denitrification, nitrification and anammox. Nitrate, nitrite and ammonium are prognostic variables. The model has been developed to resolve the biogeochemical processes of the eastern boundary upwelling systems under oxic, hypoxic and suboxic conditions.

We employ a 2-way nesting procedure (Debreu et al., 2012) to embed a small regional domain within a large-scale domain. The large domain extends from 69 to about $120^{\circ} \mathrm{W}$ in longitude and from $18^{\circ} \mathrm{N}$ to $40^{\circ} \mathrm{S}$ in latitude (Fig. S1 in the Supplement). It features a horizontal resolution of $1 / 4^{\circ}$. The embedded domain features a high-resolution grid of $1 / 12^{\circ}$ and extends from around $5^{\circ} \mathrm{N}$ to $31^{\circ} \mathrm{S}$ in latitude and around 69 to $102^{\circ} \mathrm{W}$ in longitude (Fig. 1). Both domains feature 32 vertical levels. The underlying topographies of both large-scale and regional domains are derived from the GEBCO (General Bathymetric Chart of the Oceans) at $1 \mathrm{~min}$ resolution (IOC, IHO and BODC, 2003).

The ROMS model is forced at the surface with monthly climatological fluxes of heat and fresh water from COADS (Worley et al., 2005). Wind fields are from QuikSCAT (Liu et al., 1998). At its boundaries, the large-scale domain is nudged toward monthly climatological (1990-2010) SODA reanalysis (Carton and Giese, 2008). The BioEBUS model is constrained at the boundary with monthly climatologi- cal nitrate and oxygen from CARS (Ridgway et al., 2002). The phytoplankton boundary condition is derived from the monthly climatological surface chlorophyll data from SeaWiFs (O'Reilly et al., 1998). These surface chlorophyll data are then extrapolated vertically following the Morel and Berthon (1989) parameterization (Gutknecht et al., 2013). The lateral boundary conditions for zooplankton forcing is based on an analytical function, depending on the vertical distribution of chlorophyll (Gutknecht et al., 2013). For the analysis in this paper, physical and biogeochemical dynamics of the ETSP are averaged over 5 years of simulations after a spin-up time of 25 climatological years.

\subsection{Model evaluation}

Figure 1 shows the simulated physical dynamics of the ETSP along with respective observations. At the surface, the simulated eddy kinetic energy (EKE) is increased along the coast (Fig. 1a). This pattern is in agreement with the observed surface EKE derived from an AVISO altimetry product (http://www.aviso.altimetry.fr/duacs/) over a period from 1993 to 2012 (Fig. 1b). Despite the fact that the model captures the general patterns of surface EKE, some differences are notable between the simulated and observed dynamics. These discrepancies might be related to biases both in the AVISO data (due to the proximity to the coast, Strub, 2001; Saraceno et al., 2008) and the model solution.

The surface currents, namely the Peru oceanic current (POC) in the open ocean and the Peru coastal current (PCC), transport southern-origin waters north-westward, contributing to the westward South Equatorial Current (SEC, contours in Fig. 1a, b). Along the coast, the model solution shows a southward flow at the subsurface layers (Fig. 1c, e), in agreement with the observations (Fig. 1d, f, Chaigneau et al., 2013). In the north, the southward Equator-Peru coastal current (EPCC) is intensified in the upper $150 \mathrm{~m}$ depth (Fig. 1c, d). This alongshore current is still present $150 \mathrm{~km}$ offshore, with velocities around $5 \mathrm{~cm} \mathrm{~s}^{-1}$. Further south, the simulated subsurface Peru-Chile undercurrent (PCUC, Fig. 1e) is deeper (between 50 and $250 \mathrm{~m}$ depth) and more intensified than the EPCC (Fig. 1c, d). An equatorward flow inshore is also visible in the simulated dynamics (Fig. 1e) and is consistent with the observations presented by Thomsen et al. (2016). This equatorward flow is related to the northward PCC observed along the coast (Smith, 1986; Thomsen et al., 2016). The equatorward current is observed between the surface down to about $60 \mathrm{~m}$ depth. Despite the good representation of the alongshore currents, the model underestimates the intensity of both the EPCC and the PCUC. There are many factors that might have contributed to this discrepancy, among them the low resolution of the boundary conditions used in this simulation and the smoothed bottom topography of the model.

Figure 2 presents the spatial distribution of simulated and observed biogeochemical dynamics. The simulated (Fig. 2a) 


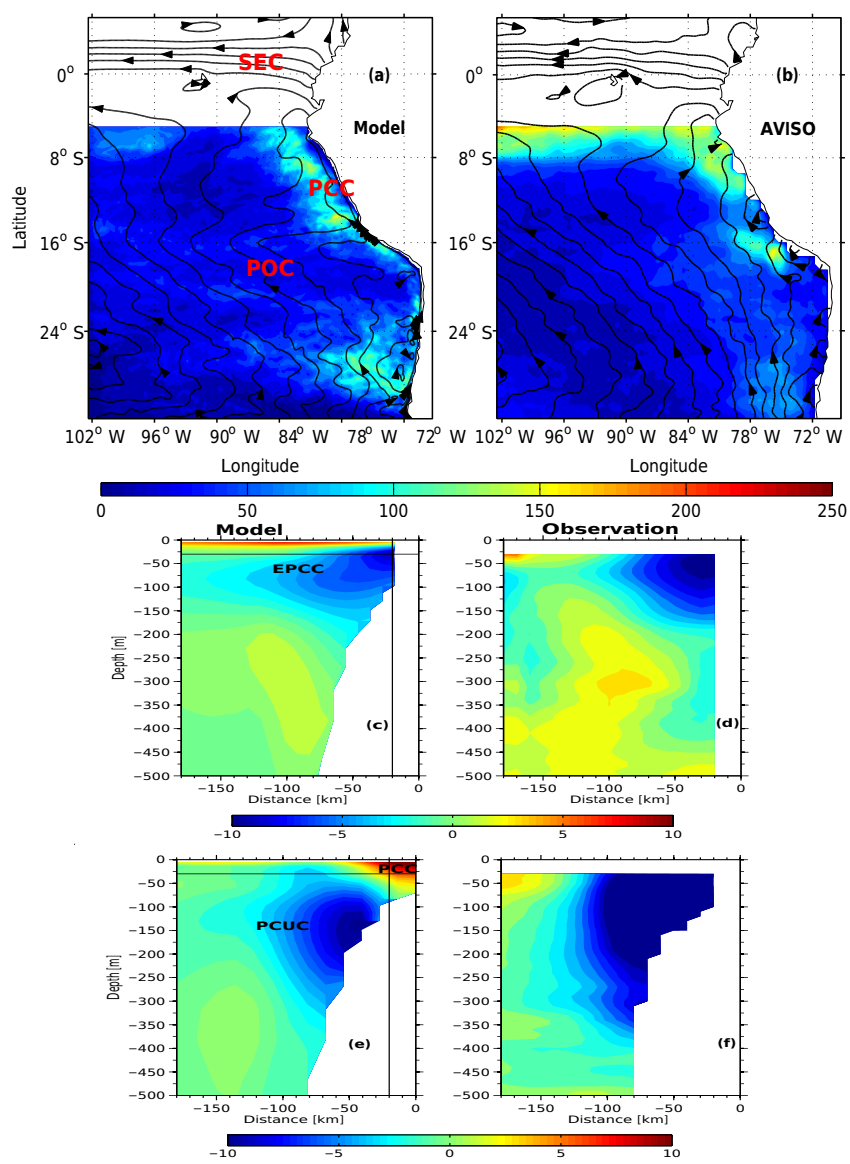

Figure 1. Annual mean surface height (contour every $6 \mathrm{~cm}$ ) overlaid on eddy kinetic energy $\left(\mathrm{cm}^{-2} \mathrm{~s}^{-2}\right.$, colour), corresponding to (a) model simulation and (b) AVISO observation. Vertical distribution of simulated $(\mathbf{c}, \mathbf{e})$ and observed $(\mathbf{d}, \mathbf{f})$ mean alongshore velocity $\left(\mathrm{cm} \mathrm{s}^{-1}\right)$, averaged over $3-6^{\circ} \mathrm{S}(\mathbf{c}, \mathbf{d})$ and at around $12^{\circ} \mathrm{S}(\mathbf{e}$, f). The black lines in (c, e) are the upper and onshore limits of the observed velocities. The observed velocities in $(\mathbf{d}, \mathbf{f})$ were provided by IMARPE and described in detail by Chaigneau et al. (2013).

as well as the remotely sensed (MODIS) surface chlorophyll (Fig. 2b, Zibordi et al., 2006) show high concentrations along the coast. The highest values are observed along the Peru upwelling region (between 5 and $16^{\circ} \mathrm{S}$ ) and are related to the upward transport of deep nutrient-rich waters (Chavez et al., 2008). Although the representation of patterns of surface chlorophyll is generally good, there are biases offshore where simulated concentrations exceed the observations. We speculate that this model deficiency is related to iron limitation (cf. Hutchins et al., 2002), which we do not explicitly account for in our current model. The simulated oxygen content at $300 \mathrm{~m}$ depth is relatively high around the equator, as shown in the observed dynamics (Fig. 2c, d). Vertically, the oxygen distribution shows less oxygenated waters at intermediate depths (Fig. 3a), in line with observations (Czeschel et al., 2011, 2015). The simulated nitrate concentrations closely match the observed vertical nitrate distribu-

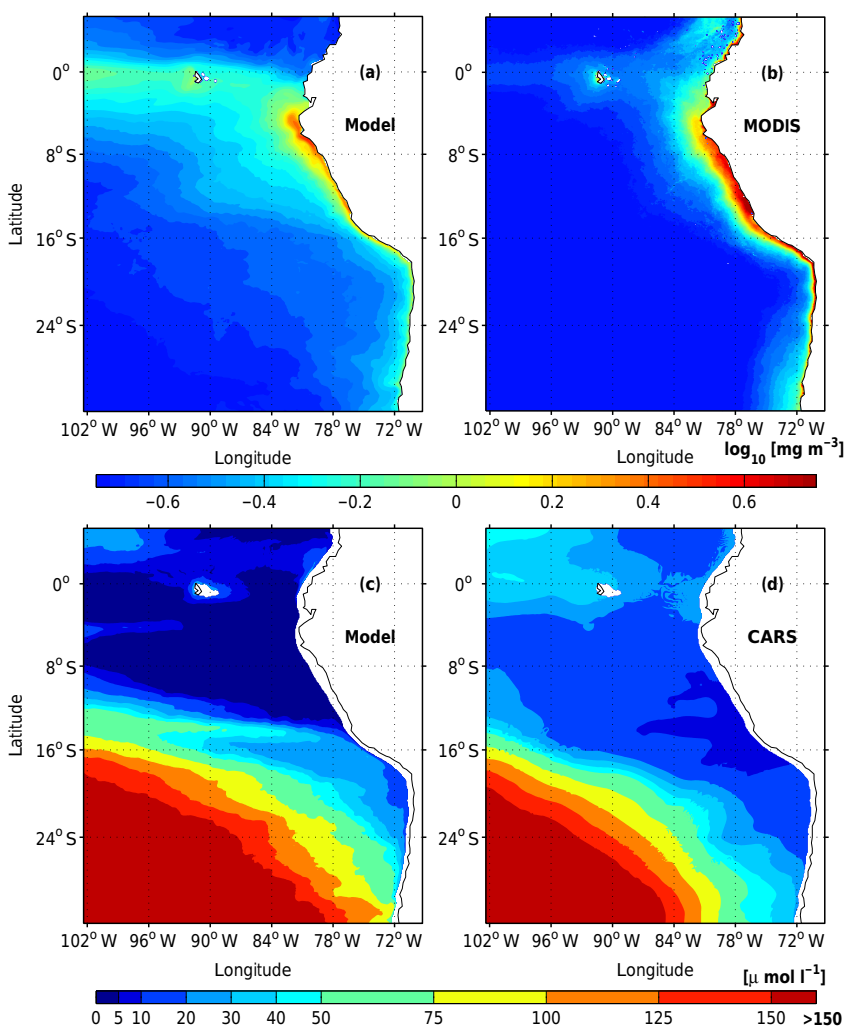

Figure 2. Sea surface chlorophyll concentration (in $\log _{10}, \mathrm{mg} \mathrm{m}^{-3}$ ) corresponding to (a) model simulation and (b) MODIS observation. Oxygen concentration at $300 \mathrm{~m}$ depth $\left(\mu \mathrm{mol} \mathrm{L}^{-1}\right)$ corresponding to (c) model simulation and (d) CARS observation.

tion, except for the deeper nitrate that is underestimated in the simulated dynamics (Fig. 3b). The vertical structure of nitrite concentrations shows high values inshore and in the subsurface layer (Fig. 3c). This is in agreement with the observations (Fig. 3c). However, the magnitude of simulated inner-shelf nitrite is lower compared to the observations.

\subsection{The eddy identification}

To analyse the source of nutrients within anticyclonic eddies, we identified two anticyclonic eddy types in the simulated physical-biogeochemical dynamics (Figs. 4 and 5). Note that the patterns of the selected eddies are consistent with the in situ observed biogeochemical patterns presented by Stramma et al. (2013). In this study, Stramma et al. (2013) have two anticyclonic mode-water eddies featuring different nutrient patterns at the subsurface layer. One eddy, which was located on the shelf, presented high nitrate and low nitrite in its centre. The second long-lived offshore eddy exhibited high nitrate and high nitrite concentration in its centre. Once identified, we tracked the eddies on time and analysed both physical and biogeochemical dynamics within the eddy structure.

The determination of eddy shape is defined based on a combination of closed contours of the sea surface height 


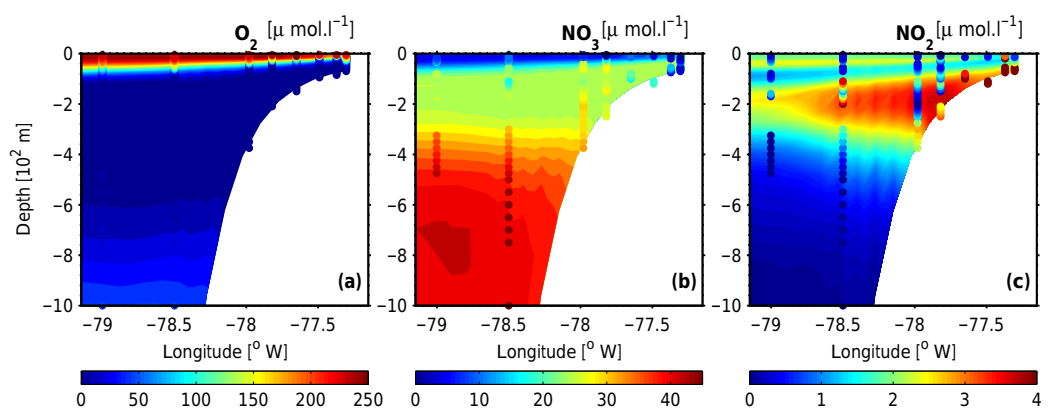

Figure 3. Vertical section of oxygen $\left(\mu \mathrm{molL}^{-1}, \mathbf{a}\right)$, nitrate $\left(\mu \mathrm{molL}^{-1}, \mathbf{b}\right)$ and nitrite $\left(\mu \mathrm{mol} \mathrm{L}^{-1}, \mathbf{c}\right)$ concentrations along $12^{\circ} \mathrm{S}$. Simulated dynamics correspond to climatological December.The observed dynamics is based on measurements from the cruise M91, December 2012. Details about this cruise are described in Czeschel et al. (2015).
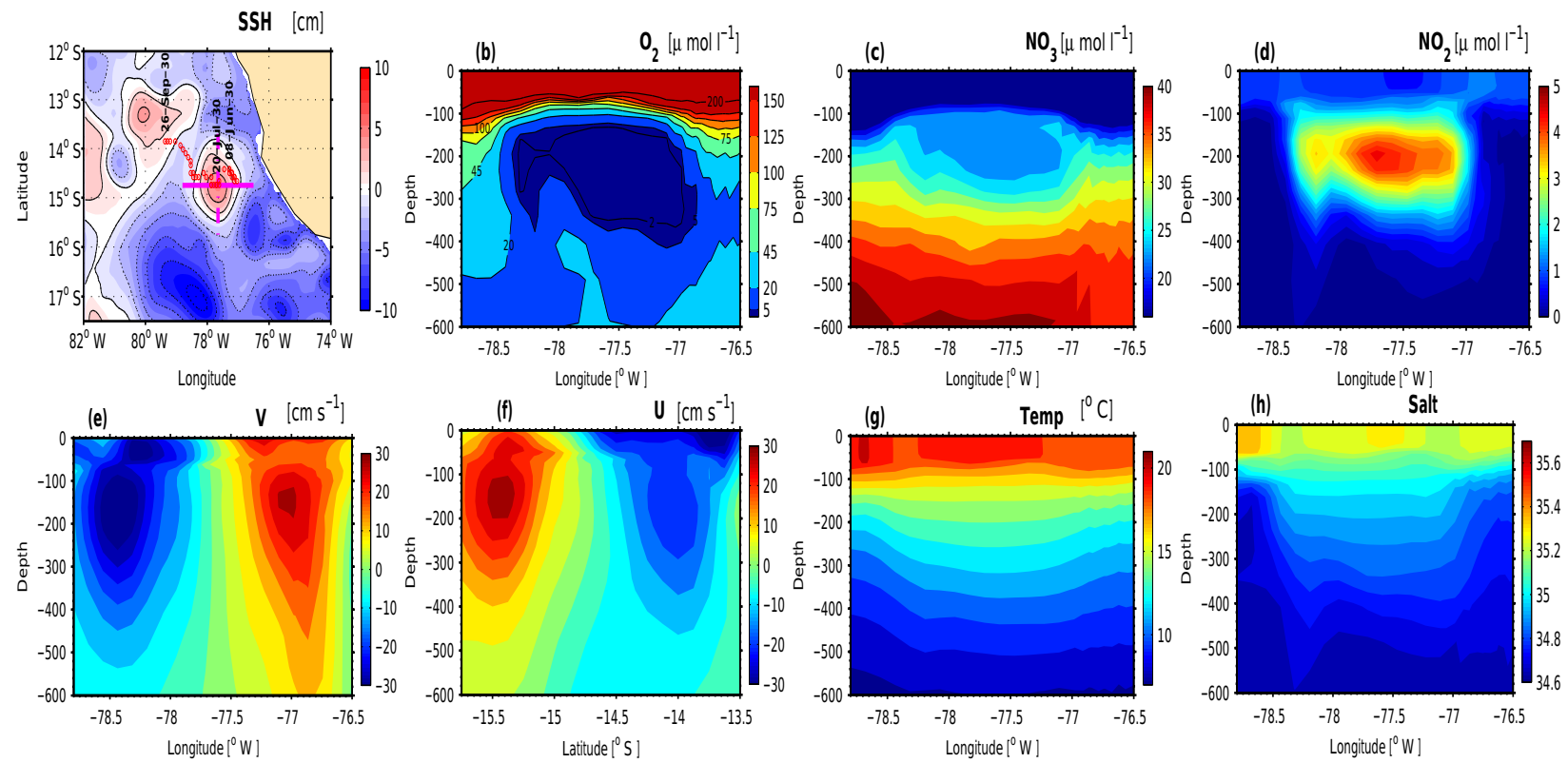

Figure 4. (a) Sea surface height $(\mathrm{cm})$, (b) oxygen $\left(\mu \mathrm{molL}^{-1}\right)$, (c) nitrate $\left(\mu \mathrm{molL}^{-1}\right)$, (d) nitrite $\left(\mu \mathrm{molL}^{-1}\right)$ concentrations, $(\mathbf{e})$ meridional velocities $\left(\mathrm{cm} \mathrm{s}^{-1}\right)$, (f) zonal velocities $\left(\mathrm{cm} \mathrm{s}^{-1}\right),(\mathbf{g})$ temperature $\left({ }^{\circ} \mathrm{C}\right)$ and (h) salinity across the eddy $A_{\text {sim }}$ centre. Nitrate, oxygen, nitrite, temperature, salinity and meridional velocity section around $14.75^{\circ} \mathrm{S}$ (magenta full line in a). Section for zonal velocity around $77.65^{\circ} \mathrm{W}$ (magenta dashed line in a). This dynamic corresponds to 21 July model year 30 . The temporal evolution of the eddy is indicated by the red dots.

(SSH) anomalies and the Okubo-Weiss parameter (José et al., 2014; Halo et al., 2014). The eddy shape is denoted by the largest connected area inside a closed contour of SSH (Chelton et al., 2011) where vorticity dominates strain (i.e where the Okubo-Weiss parameter is negative, Chelton et al., 2007). Combining the closed contours and the negative Okubo-Weiss parameter allows uncertainties associated with either method to be reduced (Halo et al., 2014).

\subsubsection{Subsurface low-nitrate and high-nitrite eddy $\left(A_{\text {sim }}\right)$}

The simulated eddy $A_{\text {sim }}$ is located at the southern part of the Peruvian coast, between 13.5 and $15.5^{\circ} \mathrm{S}$ in latitude and 76 and $78^{\circ} \mathrm{W}$ in longitude (Fig. 4a). This eddy features oxygen-depleted intermediate waters (between 100 and $400 \mathrm{~m}$ depth) in its centre, with values below $20 \mu \mathrm{molL}^{-1}$ (Fig. 4b). Nitrate-reduced waters also appear in the centre of the eddy (Fig. 4c), apparently indicative of ongoing denitrification within the structure, as suggested in previous studies (Altabet et al., 2012; Stramma et al., 2013). At the edge of the structure, the nitrate concentration is higher compared to the concentrations in the centre of the eddy (Fig. 4c). This high nitrate at the edge might be entrained from the surrounding environment by horizontal stirring. In contrast, the nitrite concentration is higher in the centre and low at the edge (Fig. 4d). 

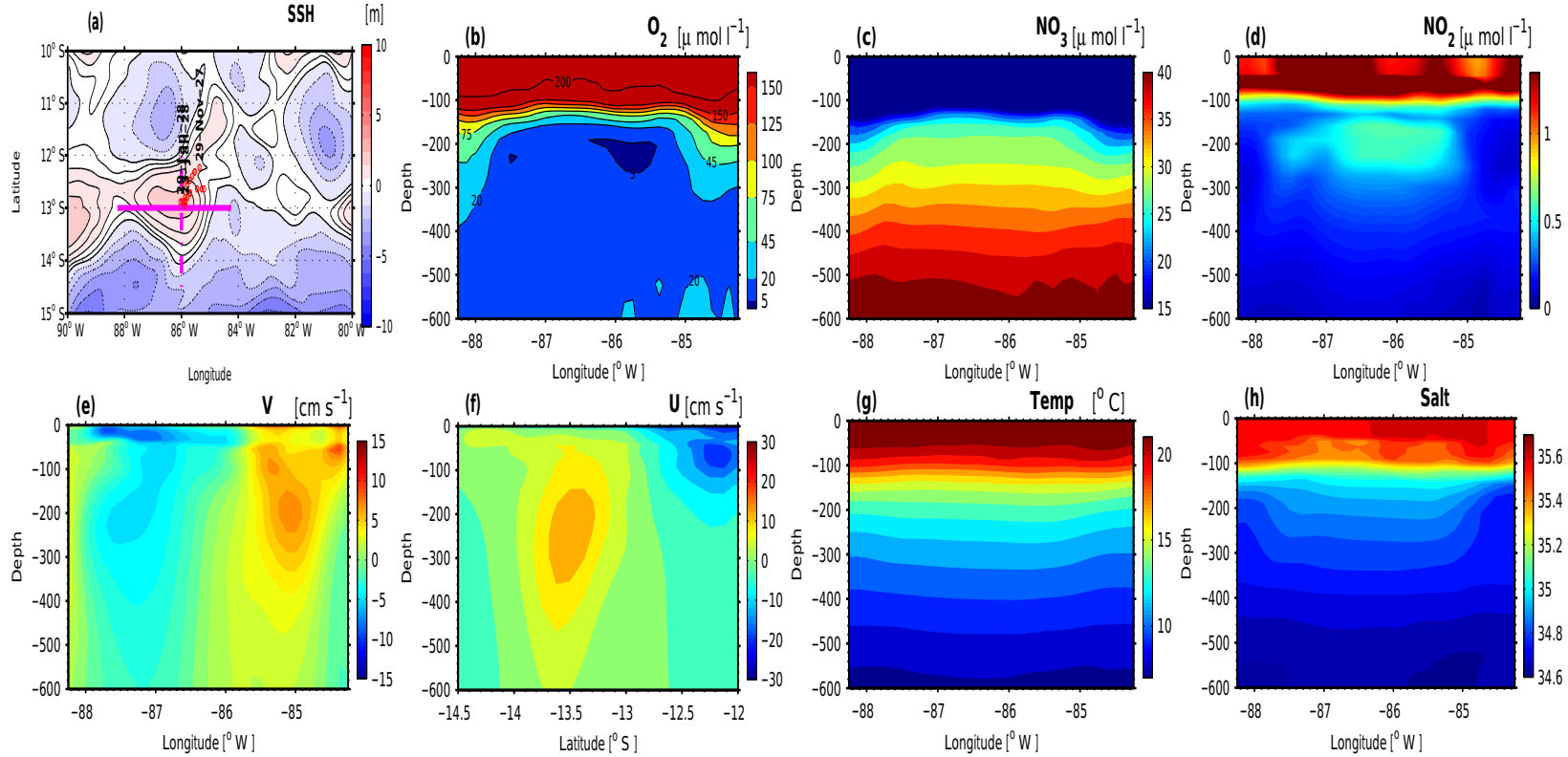

Figure 5. (a) Sea surface height $(\mathrm{cm})$, (b) oxygen $\left(\mu \mathrm{molL}^{-1}\right)$, (c) nitrate $\left(\mu \mathrm{molL}^{-1}\right)$, (d) nitrite $\left(\mu \mathrm{molL} \mathrm{L}^{-1}\right)$ concentrations, $(\mathbf{e}) \mathrm{meridional}$ velocities $\left(\mathrm{cm} \mathrm{s}^{-1}\right)$, (f) zonal velocities $\left(\mathrm{cm} \mathrm{s}^{-1}\right),(\mathbf{g})$ temperature $\left({ }^{\circ} \mathrm{C}\right)$ and $(\mathbf{h})$ salinity across the eddy $B_{\text {sim }}$ centre. Nitrate, oxygen, nitrite, temperature, salinity and meridional velocity section around $13.2^{\circ} \mathrm{S}$ (magenta full line in a). Section for zonal velocity around $85.8^{\circ} \mathrm{W}$ (magenta dashed line in a). This dynamics corresponds to 27 January model year 28 . The temporal evolution of the eddy is indicated by the red dots.

Generated in the southern part of the Peruvian shelf (around $14.5^{\circ} \mathrm{S}$ ) about 42 days before the instant presented in Fig. 4 , the eddy $A_{\text {sim }}$ propagates north-westward. This eddy genesis and propagation is in agreement with altimetry observations (Chaigneau et al., 2008). The eddy $A_{\text {sim }}$ is intensified from the surface down to $500 \mathrm{~m}$ depth, with maximum velocity above $30 \mathrm{~cm} \mathrm{~s}^{-1}$ (Fig. 4e, f). Further, the eddy $A_{\text {sim }}$ presents a subsurface velocity maxima, similar to the observed patterns within anticyclonic eddies in the ETSP (Chaigneau et al., 2011; Holte et al., 2013; Stramma et al., 2013; Thomsen et al., 2016). This characteristic is related to the poleward-flowing PCUC (Chaigneau et al., 2011; Colas et al., 2012; Holte et al., 2013). Temperature and salinity show depressed isolines in the centre of the eddy (Fig. 4g, h), typical of a mode-water anticyclonic eddy.

\subsubsection{Subsurface high-nitrate and -nitrite eddy $\left(B_{\text {sim }}\right)$}

The simulated eddy $B_{\text {sim }}$ is an open-ocean eddy, located between 12 and $14.5^{\circ} \mathrm{S}$ in latitude and 84 and $88^{\circ} \mathrm{W}$ in longitude (Fig. 5a). This eddy also presents extremely low oxygen concentrations at intermediate depths in its centre (Fig. 5b), which is similar to eddy $A_{\text {sim. }}$. The oxygen-depleted waters are enclosed by well-oxygenated waters at the eddy's edge (Fig. 5b). The eddy $B_{\text {sim }}$ shows increased subsurface nitrate concentrations in the centre and slightly reduced nitrate concentrations along the edge (Fig. 5c). The vertical structure of nitrite concentrations shows isolated subsurface high-nitrite waters in the centre of the eddy (Fig. 5d). Despite reproduc- ing the subsurface nitrite maxima, the simulated concentrations are an order of magnitude lower compared to the in situ observations of nitrite concentration within eddy (Stramma et al., 2013).

The age of eddy $B_{\text {sim }}$ is about 2 months (54 days) and it was generated offshore near to $85^{\circ} \mathrm{W}$ and $12^{\circ} \mathrm{S}$. The place of generation of model eddy $B_{\text {sim }}$ is in agreement with the eddy genesis inferred from the altimetry observations (Chaigneau et al., 2008). After possibly being detached from a meandertype structure, the eddy $B_{\text {sim }}$ propagates westward and is deflected poleward. Figure 5e and f show the vertical section of the eddy $B_{\text {sim }}$ velocities. Maximum velocities are found at the surface layers in the westward flow and at the subsurface layers in the eastward flow. This circulation pattern is similar to the observed velocity within anticyclonic eddies in this region (Chaigneau et al., 2011; Holte et al., 2013; Stramma et al., 2013; Thomsen et al., 2016) and is likely linked to the dynamics of the PCUC (Chaigneau et al., 2011; Colas et al., 2012; Holte et al., 2013). The eddy $B_{\text {sim }}$ shows elevated temperature and salinity in the centre, characteristics of a mode-water anticyclonic eddy (Fig. 5g, h). The warmer and saltier waters within the mode-water eddies are related to the depression of the lower isotherms and isohalines in the interior of the structure. 

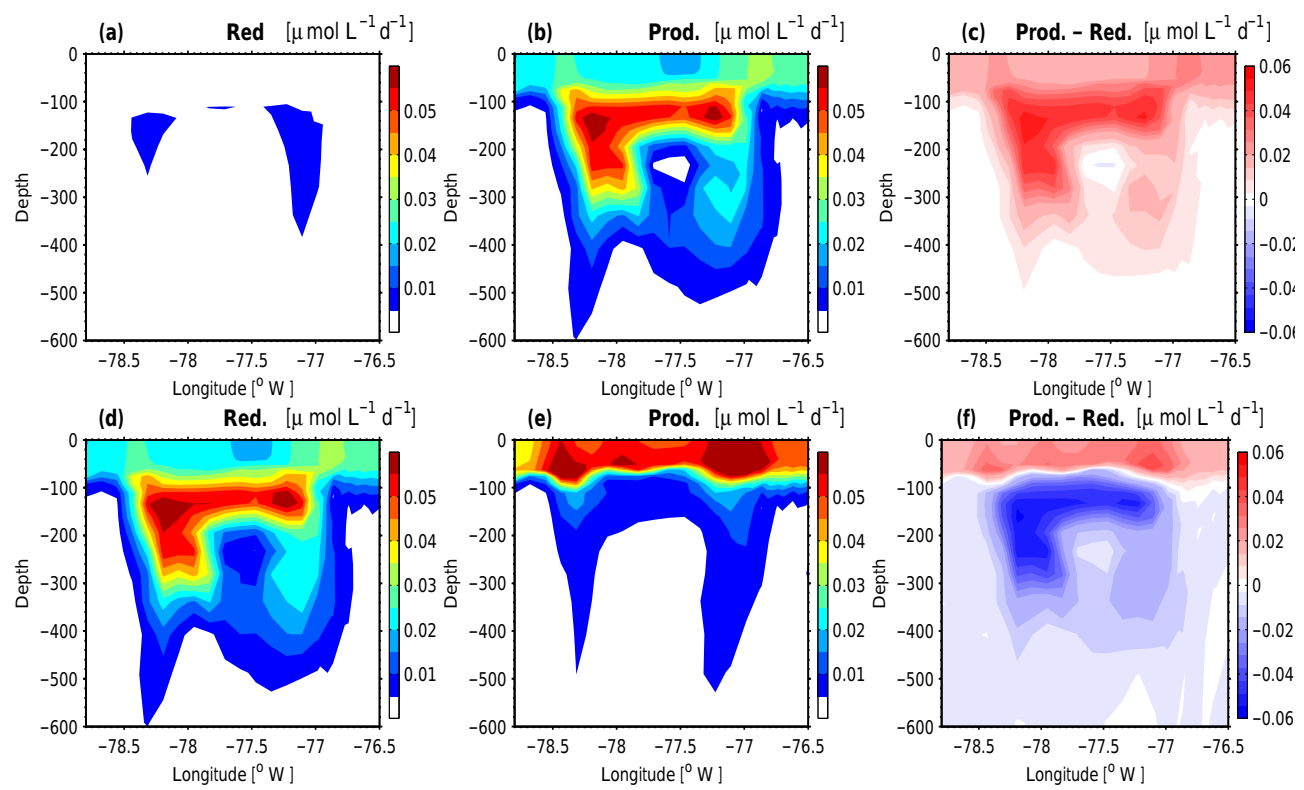

Figure 6. Eddy $A_{\text {sim }}$ vertical structure of (a) nitrate reduction by denitrification $\left(\mu \mathrm{mol} \mathrm{L}^{-1} \mathrm{~d}^{-1}\right)$, (b) nitrate production by nitrification $\left(\mu \mathrm{mol} \mathrm{L} \mathrm{L}^{-1} \mathrm{~d}^{-1}\right)$, (c) nitrate production-reduction difference $\left(\mu \mathrm{molL} \mathrm{L}^{-1} \mathrm{~d}^{-1}\right)$, (d) nitrite reduction (nitrification + denitrification + anammox, $\mu \mathrm{molL}^{-1} \mathrm{~d}^{-1}$ ), (e) nitrite production (denitrification + nitrification, $\mu \mathrm{molL}^{-1} \mathrm{~d}^{-1}$ ) and (f) nitrite production-reduction difference $\left(\mu \mathrm{molL} \mathrm{L}^{-1} \mathrm{~d}^{-1}\right)$ at the instant shown in Fig. 4.

\subsection{Analysis of physical and biogeochemical dynamics within the eddy}

In order to have insights into the processes controlling the nutrient distribution within the eddies, the advective transport (vertical and horizontal), sources and sinks of nutrients (referred in the text as the local biogeochemical processes) are analysed during the eddy evolution. The time evolution of nutrient concentrations is also presented. The eddy volume is defined here as the volume between 100 and $200 \mathrm{~m}$ within the eddy shape (Fig. S2 in the Supplement for further details). The horizontal advective transport of nutrients is calculated at the edge of the eddy structure, while the vertical transport is calculated at the upper $(100 \mathrm{~m})$ and lower $(200 \mathrm{~m})$ extremes of the eddy volume. The nutrient concentration, as well as the nutrient sources and sinks correspond to the averaged quantities within the eddy volume. The sources and sinks of nitrate consist of nitrification and denitrification, respectively. For nitrite, multiple sources and sinks are accounted. The sources are denitrification and nitrification, while the sinks consist of nitrification, denitrification and anammox.

\subsection{Particle-release experiment}

In order to have a more general overview of the processes controlling the dynamics of the eddies in the ETSP, we conduct particle-release experiments and analyse the anticyclonic eddies that are in the vicinity of the particle-release locations at the time of the release. In these experiments, particles are released in three different locations in ETSP:
(1) along the shelf between 3 and $15^{\circ} \mathrm{S}$, (2) along the shelf between 9 and $11^{\circ} \mathrm{S}$ and (3) offshore between 13 and $15^{\circ} \mathrm{S}$ in latitude and $85-86^{\circ} \mathrm{W}$ (Fig. S3 in the Supplement). The particles are released in the entire water column on the shelf and in the upper $300 \mathrm{~m}$ at the offshore site, in early austral summer (January) and early winter (June) of the last three climatological years of the model simulation.

\section{Results}

\subsection{Local biogeochemical dynamics within the eddies}

In order to assess the contribution of local biogeochemical dynamics to nutrient variations within the eddy, we analyse here the production and reduction rates of each nutrient at the instant shown in Figs. 4 and 5. Note that the magnitude of simulated nutrient production and reduction rates, which varies from 0.01 to $1 \mu \mathrm{mol} \mathrm{L}^{-1} \mathrm{~d}^{-1}$ (Figs. 6 to 9), are in the range of the observed denitrification, nitrification and anammox rates in the upwelling system off Peru (Ward et al., 2009; Kalvelage et al., 2013). Figure 6 shows the vertical distribution of reduction and production rates of nitrate (Fig. 6a-b) and nitrite (Fig. 6d-e) within the eddy $A_{\text {sim. }}$. The net production (production-reduction) is also presented, for both nitrate (Fig. 6c) and nitrite (Fig. 6f). Below the surface of the eddy $A_{\text {sim }}$, the nitrate reduction by denitrification (Fig. 6a) is lower when compared to the production by nitrification (Fig. 6b), showing a net nitrate increase due to biogeochemical processes within the eddy (Fig. 6c). Regarding 

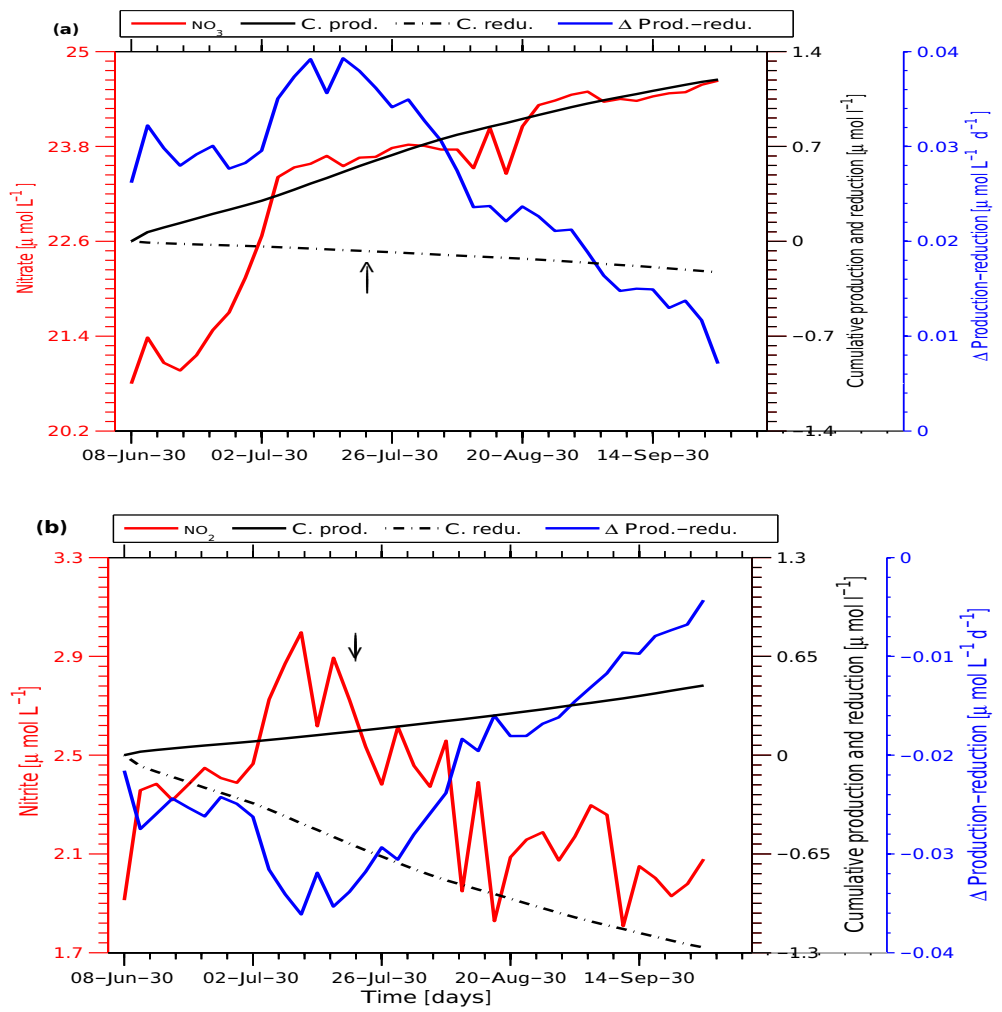

Figure 7. (a) Time evolution of cumulative production (full black line, $\mu \mathrm{molL}^{-1}$ ), cumulative reduction (dashed black line, $\mu$ mol $\mathrm{L}^{-1}$ ), production-reduction difference (blue line, $\mu \mathrm{molL}^{-1}$ ) and available nitrate (red line, $\mu \mathrm{mol} \mathrm{L}^{-1}$ ) within the subsurface layer of the eddy $A_{\text {sim. }}$ (b) The same as (a) but for nitrite. The concentration and fluxes in (a, b) correspond to averaged quantities between 100 and $200 \mathrm{~m}$ layer within the eddy structure. Arrow indicates the time when the sections in Fig. 4 were made.
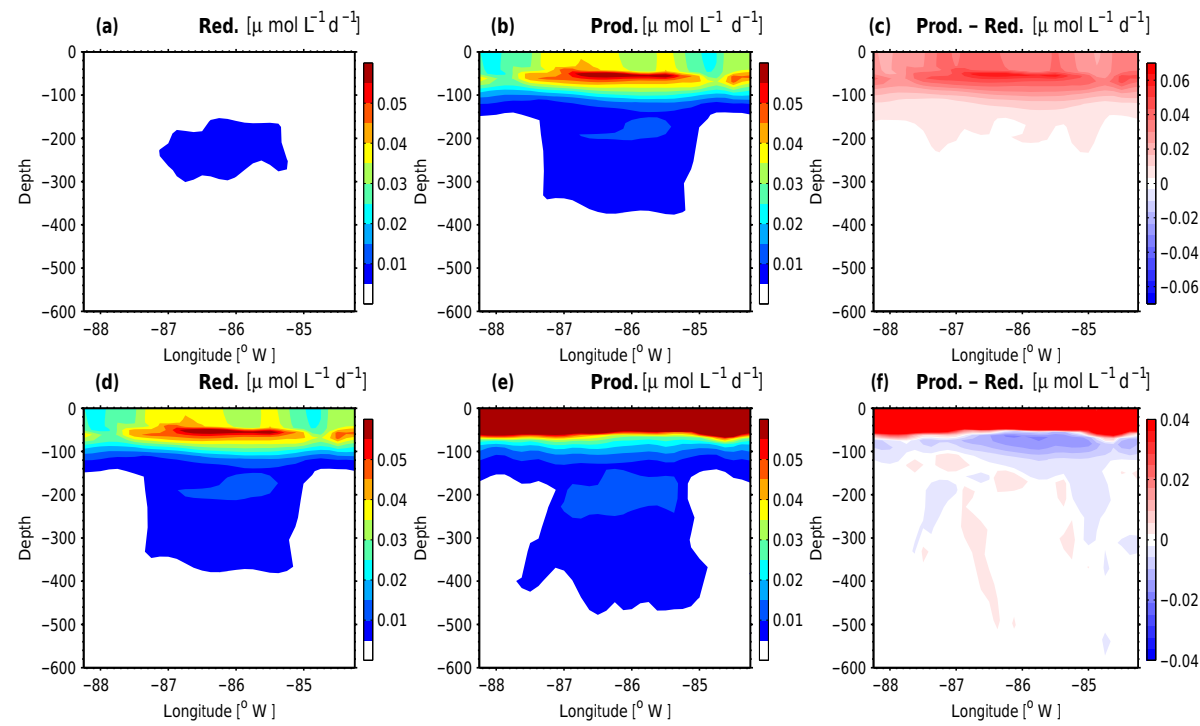

Figure 8. Eddy $B_{\text {sim }}$ vertical structure of (a) nitrate reduction by denitrification $\left(\mu \mathrm{molL}^{-1} \mathrm{~d}^{-1}\right)$, (b) nitrate production by nitrification $\left(\mu \mathrm{molL} \mathrm{L}^{-1} \mathrm{~d}^{-1}\right),(\mathbf{c})$ nitrate production-reduction difference $\left(\mu \mathrm{mol} \mathrm{L}^{-1} \mathrm{~d}^{-1}\right),(\mathbf{d})$ nitrite reduction (nitrification + denitrification + anammox, $\mu \mathrm{molL}^{-1} \mathrm{~d}^{-1}$ ), (e) nitrite production (denitrification + nitrification, $\mu \mathrm{molL}^{-1} \mathrm{~d}^{-1}$ ) and (f) nitrite production-reduction difference $\left(\mu \mathrm{molL} \mathrm{L}^{-1} \mathrm{~d}^{-1}\right)$ at the instant shown in Fig. 5. 

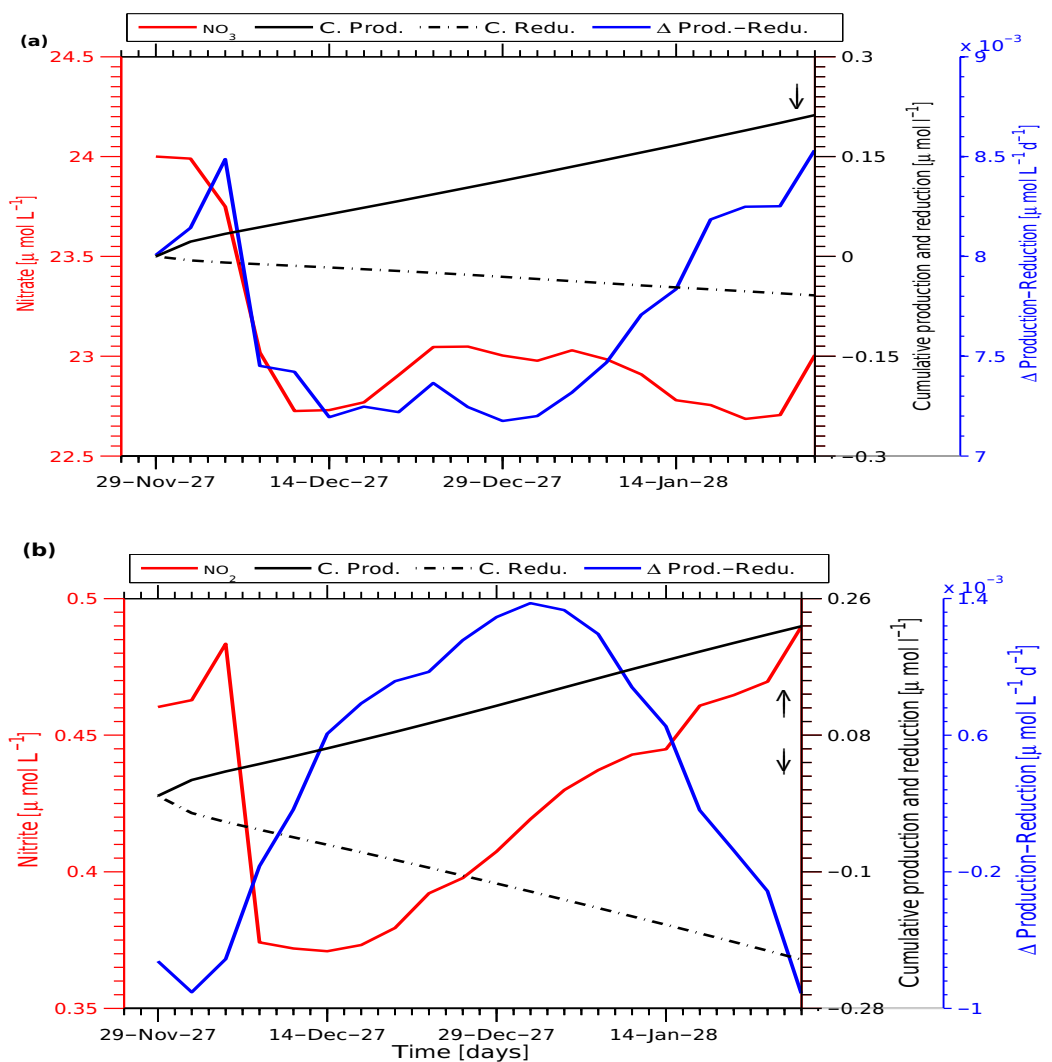

Figure 9. (a) Time evolution of cumulative production (full black line, $\left(\mu \mathrm{molL}^{-1}\right)$, cumulative reduction (dashed black line, $\left.\mu \mathrm{molL} \mathrm{L}^{-1}\right)$, production-reduction difference (blue line, $\mu \mathrm{mol} \mathrm{L} \mathrm{L}^{-1} \mathrm{~d}^{-1}$ ) and available nitrate (red line, $\mu \mathrm{mol} \mathrm{L}-1$ ) within the subsurface layer of the eddy $B_{\text {sim. }}$ (b) The same as (a) but for nitrite. The concentration and fluxes in (a, b) correspond to averaged quantities between 100 and $200 \mathrm{~m}$ depth layer within the eddy structure. Arrow indicates the time when the sections in Fig. 5 were made.

the nitrite dynamics, production (by nitrification and denitrification) and reduction (by nitrification, denitrification and anammox) rates show similar patterns. Below the surface, the nitrite reduction is slightly higher than the production (Fig. 6d-f), suggesting that local biogeochemical processes can not explain the accumulation of high nitrite values in the centre of this eddy (Fig. 4d). Figure 7 shows the time evolution of production and reduction rates of both nutrients (nitrate and nitrite) within the eddy $A_{\text {sim. }}$. For comparison, nutrient concentrations during this period are also presented. Both reduction and production of nutrients within the eddy do not show any trend that could explain the reduced nitrate in the centre of the eddy. The nitrate production is higher than the reduction, showing a net increase of nitrate due to biogeochemical processes within the eddy $A_{\text {sim }}$ (Fig. 7a). But the magnitude of the locally produced nitrate is low compared to total changes in nitrate concentration during the eddy propagation. Local nitrite reduction is higher than local production during the eddy propagation (Fig. 7b). The pattern of local net nitrite production is not correlated with the total changes in nitrite concentrations. These results show that the low nitrate (high nitrite) within the eddy $A_{\text {sim }}$ is not primarily con- trolled by local biogeochemical dynamics within the eddy $A_{\text {sim. }}$.

In the eddy $B_{\text {sim }}$, the vertical structure of production and reduction rates of nitrate show a net nitrate production in the upper layers (Fig. 8a, b, c). The local nitrate dynamics during the propagation of eddy $B_{\text {sim }}$ show elevated nitrate production in comparison to the reduction (Fig. 9a). Despite the net increase, the pattern as well as the magnitude of the locally produced nitrate do not match with changes in total nitrate concentrations. The vertical structure of nitrite production also reflects elevated values in the upper surface layer (Fig. 8d, e, f). Below the surface, nitrite reduction dominates the local dynamics, with no difference between the centre and the edge of the eddy. The nitrite dynamics during the eddy propagation show a local dominance of nitrite production within the eddy, which is inconsistent with the temporal variations of nitrite concentrations (Fig. 9b).

The inconsistency between local biogeochemical sources and sinks of nitrate and nitrite and total temporal changes of those nutrients within the eddies suggest that the biogeochemical dynamics do not exert the dominant control on the variation in nutrient concentrations. 

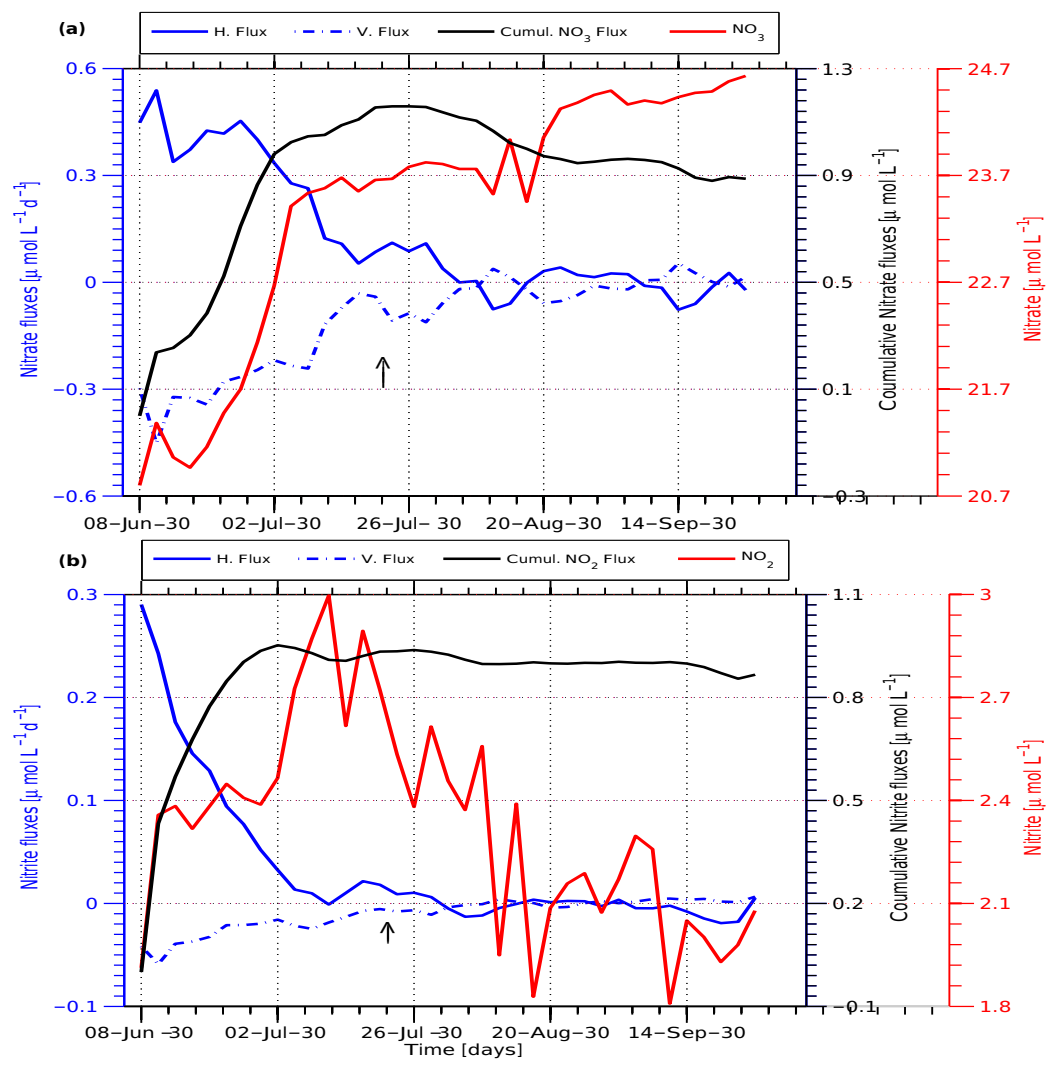

Figure 10. Nitrate (a) and nitrite (b) advective fluxes divergence into the eddy $A_{\text {sim. }}$. Lines indicate horizontal (solid blue, $\mu$ mol $\mathrm{L}^{-1} \mathrm{~d}^{-1}$ ), vertical (dashed blue, $\mu \mathrm{mol} \mathrm{L}^{-1} \mathrm{~d}^{-1}$ ) and cumulative (black, $\mu \mathrm{molL}^{-1}$ ) advective fluxes divergence. Red line represents the available nitrate (a) and nitrite (b) within the eddy $\left(\mu \mathrm{molL}^{-1}\right)$. Arrows indicate the time when the sections in Fig. 4 were taken.

\subsection{Nutrient transport and water mass properties within the eddies}

One important aspect of eddies is their capacity to entrain surrounding waters during their propagation (José et al., 2014). These dynamics have been shown to stimulate productivity within anticyclonic eddies (José et al., 2014). In the eastern tropical oceans, anticyclonic eddies have been observed to carry low-oxygen waters out of the core region of the OMZ (Stramma et al., 2014; Karstensen et al., 2015). This makes the analysis of the eddy life history essential for understanding the dynamics in the eddy interior. To investigate the origin of water masses present in the selected eddies, we analyse the advective transports of both nitrate and nitrite into the eddy during the eddy's lifetime (Figs. 10 and 12). The water mass properties within the structure are also analysed and compared with the surrounding environment during different instants of the eddy's lifetime (Figs. 11 and 13). Figure 10 illustrates the nitrate and nitrite fluxes into the eddy $A_{\text {sim. }}$. It shows a strong injection of nutrients from the lateral margins of the eddy. This nutrient injection is elevated in the first months following the eddy formation. The cumulative fluxes of both nitrate and nitrite significantly increase in this period and follow their evolution within the eddy. These dy- namics suggest a strong exchange with the surrounding environment during this period. This is also visible in the water mass properties within the eddy structure (Fig. 11). At the surface, waters present within the eddy $A_{\text {sim }}$ are relatively cool and fresh compared to the water masses present following the eddy formation (Fig. 11a-b). These waters are distinct from those from the shelf. Waters in the eddy interior show a dominance of relatively warmer and saltier surface waters compared to the shelf waters (Fig. 11a-b). When the eddy $A_{\text {sim }}$ was formed, the surface waters were even warmer and saltier, characteristic of offshore waters (Fig. S4 in the Supplement). During the propagation of eddy $A_{\text {sim }}$, the water masses within the structure are mixed with colder and fresher coastal waters, resulting in heat and salt loss (Fig. 11c). However, water masses within the eddy are still dominantly from the offshore region. The offshore region is a nitrate-poor environment, with minimum concentrations below $5 \mu \mathrm{molL}^{-1}$ (Fig. 11d). At $100 \mathrm{~m}$ depth, water masses within the eddy are relatively fresher and cooler and do not match those of the offshore environment (Fig. 11e, f). Although roughly associated with shelf waters, the water masses within the eddy at this depth are saltier and warmer than those from the shelf. At eddy formation, the water masses within the eddy were even warmer and saltier (Fig. 11g), suggesting a domi- 

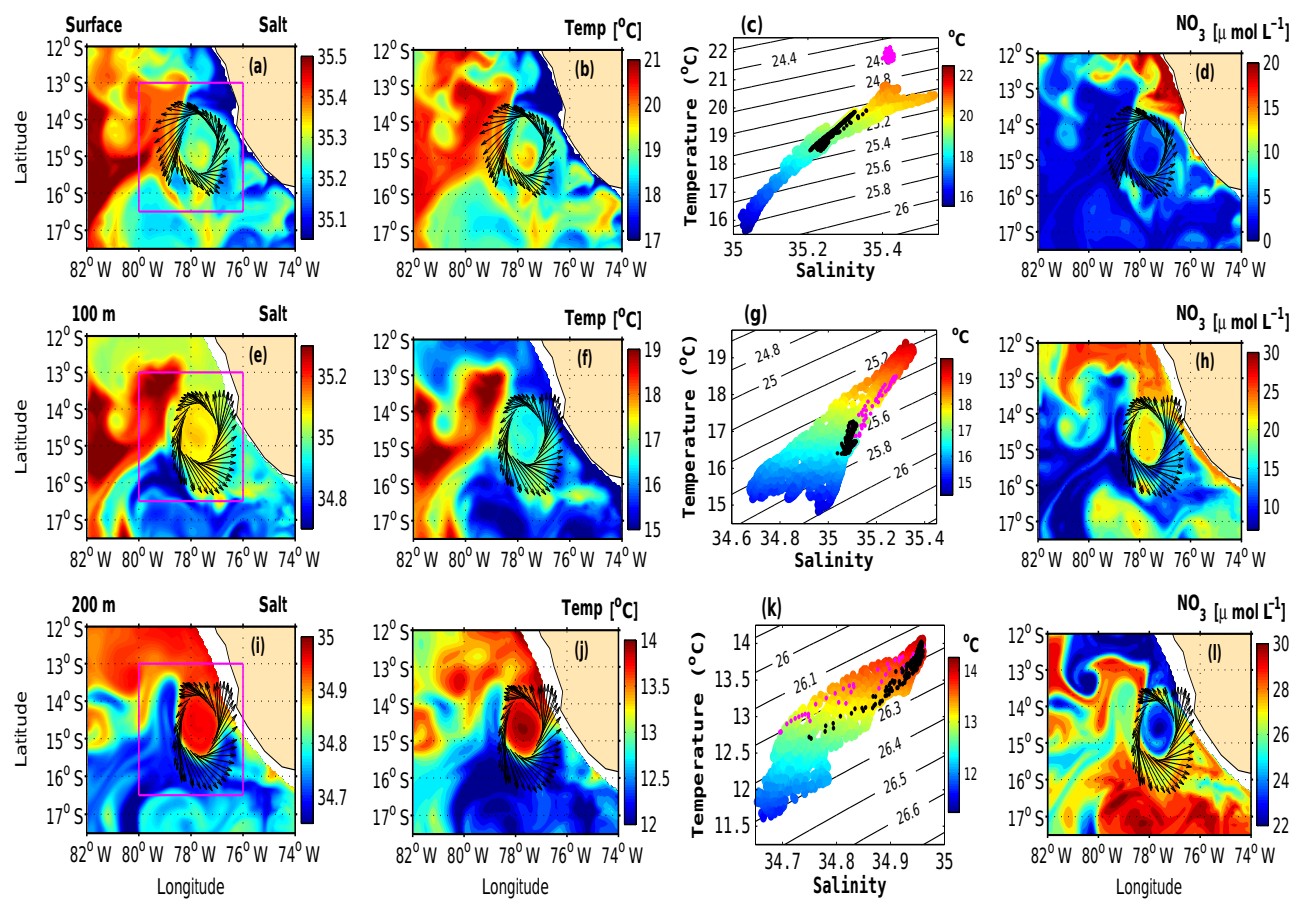

Figure 11. Water mass properties and nitrate distribution around the eddy $A_{\text {sim. }}$. Left panels: spatial distribution of simulated salinity at surface (top), $100 \mathrm{~m}$ (middle) and $200 \mathrm{~m}$ depth (bottom). Middle-left panels: the same as left panel, but for temperature. Middle-right panels: TS relation for surface (top), $100 \mathrm{~m}$ (middle) and $200 \mathrm{~m}$ depth (bottom) waters. Right panels: the same as left panels, but for nitrate. The arrows represent the circulation patterns at the eddy's edge. Black and magenta dots in the TS diagram correspond to the water masses within the eddy at the instant after the eddy formation (magenta) and the instant shown in Fig. 4 (black dots). The magenta box in (a) indicates the region over which the TS diagram is calculated.

nance of offshore waters within the structure. This suggestion is supported by the dominance of warmer and saltier offshore waters in the eddy centre right after the eddy formation (Fig. S4e, f in the Supplement). During the eddy propagation, the fresher and colder shelf waters entered the eddy interior, resulting in a cooling and freshening of the water masses within the structure. As a result, shelf waters carrying high nitrate concentrations dominate the eddy interior (Fig. 11h). Further down (at $200 \mathrm{~m}$ depth), warmer and saltier shelf waters dominate the properties within the eddy $A_{\text {sim }}$ (Fig. 11i, j). At the eddy formation, both shelf and offshore waters occupy the eddy interior (Fig. S4i-k). The surrounding offshore waters have higher concentrations of both nitrate and nitrite (Fig. S4k, 1). With the eddy propagation, water properties are modified (Fig. 11k). Shelf waters which have lower nitrate concentrations compared to the offshore environment are kept in the eddy centre and advected during the eddy propagation (Fig. 111). Thus, the nitrate concentrations in the eddy interior are lower than those of the surrounding waters, even though interior concentrations show an increase over time during the propagation of the eddy.

The nutrient fluxes across the edge of the eddy $B_{\text {sim }}$ are presented in Fig. 12. It shows a contribution of both horizontal and vertical transport to the nutrient variation within the eddy, during the eddy's lifetime. After the eddy $B_{\text {sim }}$ for- mation, the nitrate fluxes through the edge of the eddy $B_{\text {sim }}$ are dominantly outgoing, showing a loss of nitrate to the surrounding environment (Fig. 12a). These outgoing fluxes reduce the nitrate availability within the eddy. About half a month later, the nitrate concentration within the eddy increases. This increase is to a large extent due to the nitrate supply into the eddy structure from both vertical and horizontal boundaries. On the contrary, the nitrite supply into the eddy is at its largest and is positive in the month following the eddy formation, but decreases afterwards (Fig. 12b). Located far from the shelf region, the water masses within the eddy $B_{\text {sim }}$ are distinct of those from the shelf (Fig. 13). At the surface, relatively cooler and saltier waters occupy the eddy interior (Fig. 13a, b). These waters result from a mixture of saltier and cooler southern water with fresher and warmer northern waters. During the eddy propagation, intrusion of warmer northern waters increases the eddy surface water temperature (Fig. 13c). This intrusion of warmer waters can also be seen from the limb of warmer waters at the north-western side of the eddy (Fig. 13b). At $100 \mathrm{~m}$ depth, warmer and saltier southern waters occupy the eddy interior (Fig. 13e, f, g). These waters also dominate the eddy interior at the instant following the eddy formation (Fig. 11e-f). The waters of southern origin that are trapped within the eddy's interior are subsequently mixed with the fresher and colder 


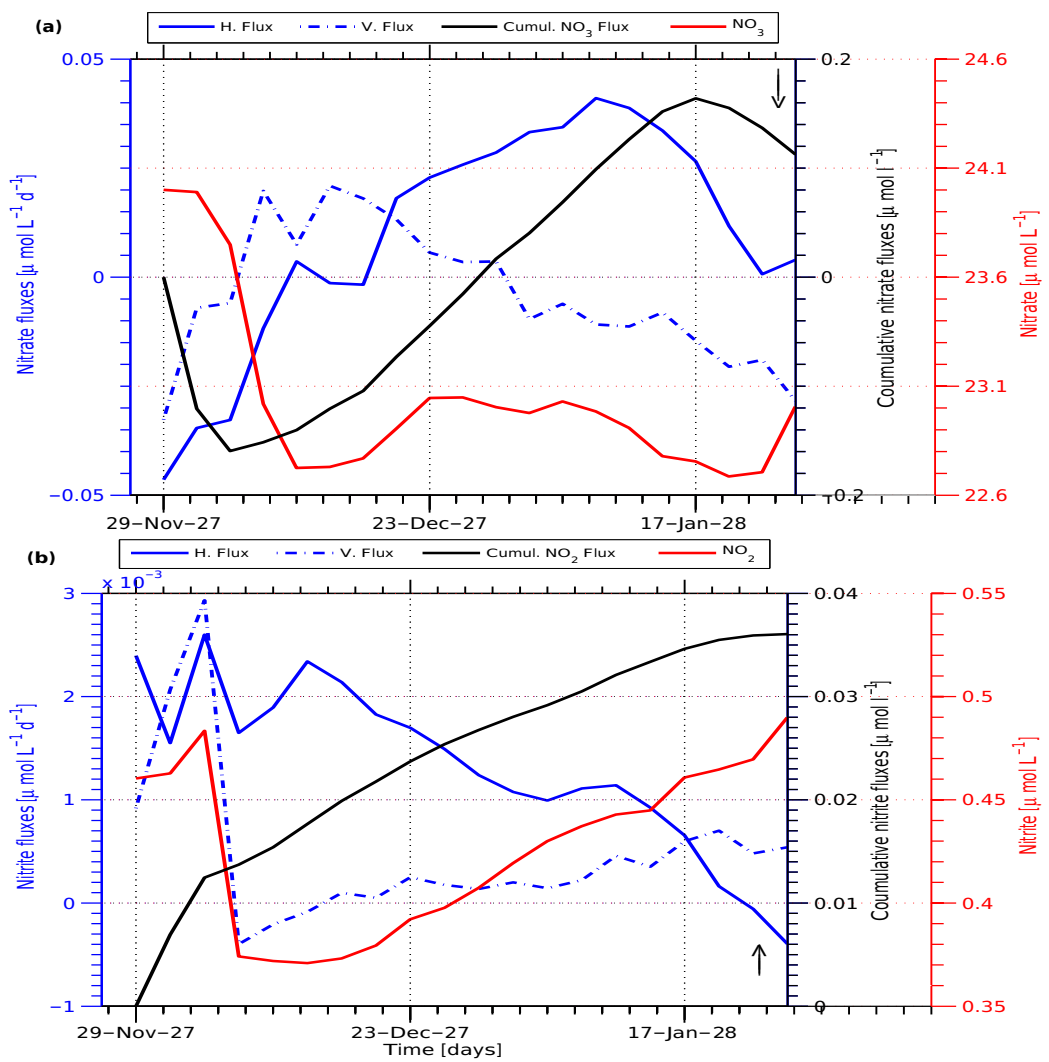

Figure 12. Nitrate (a) and nitrite (b) advective fluxes divergence into the eddy $B_{\text {sim. }}$. Lines indicate horizontal (solid blue, $\mu$ mol $\left.\mathrm{L}^{-1} \mathrm{~d}^{-1}\right)$, vertical (dashed blue, $\mu \mathrm{molL} \mathrm{L}^{-1} \mathrm{~d}^{-1}$ ) and cumulative (black, $\mu \mathrm{molL} \mathrm{L}^{-1}$ ) advective fluxes divergence. Red line represents the available nitrate (a) and nitrite (b) within the eddy $\left(\mu \mathrm{molL}^{-1}\right)$. Arrows indicate the time when the sections in Fig. 5 were taken.

northern waters, which enter the eddy by the north-western edge. However, only relatively small changes occur during the eddy propagation (Fig. 13g). Consequently, nitrate-poor southern waters are trapped within the eddy (Fig. 13h). The weak water mass exchange with surrounding waters during the eddy propagation is also visible at $250 \mathrm{~m}$ depth (Fig. 13k). Further down, warmer and saltier northern waters dominate the eddy interior (Fig. 13i, j). These waters are rich in nitrate (Fig. 13k), explaining the elevated nitrate in Fig. 5. These water mass properties and nutrient distribution are similar to those encountered within the newly formed eddy (Fig. S5i-1 in the Supplement).

\subsection{Eddy stirring and nutrient entrainment}

The eddies $A_{\text {sim }}$ and $B_{\text {sim }}$ showcase that the nutrient supply by physical dynamics is the dominant mechanism that controls simulated (diverse) nutrient patterns within the eddies. The nutrient exchange with surrounding waters occurs throughout the entire lifetime of the eddies. This indicates that the nutrient availability in the vicinity of the eddy plays a role in the nutrient distribution within the eddy's structure. To elucidate this suggestion, we carried out particle-release experiments (Sect. 2.4) and analysed the eddies that passed and/or were generated close to the particle-release areas. Figure 14 illustrates the particle distribution in the subsurface interior (between 100 and $200 \mathrm{~m}$ depth) of anticyclonic eddies during their propagation. From the early stages on, particles are entrained and trapped within the eddy structures. These particles are transported offshore during propagation of the eddies. Every tracked eddy shows a pronounced temporal variation of the amount of particles within the structure, an indicative of exchange of properties with surrounding waters. This behaviour occurs in eddies tracked during both austral summer (Fig. 14a, c, e) and austral winter (Fig. 14b, d, f).

\section{Discussion}

Subsurface anticyclonic eddies, also known as mode-water eddies, are common features in the ETSP (Chaigneau et al., 2011; Holte et al., 2013). These eddies have a weak surface signal, making it difficult to observe them from space. Based on model results, Colas et al. (2012) have found that these eddies dominate the subsurface of the ETSP. They are detached from the subsurface poleward undercurrent PCUC (Colas et al., 2012). Only recently, measurements along the Peruvian shelf have shown a direct link between PCUC and the mode- 

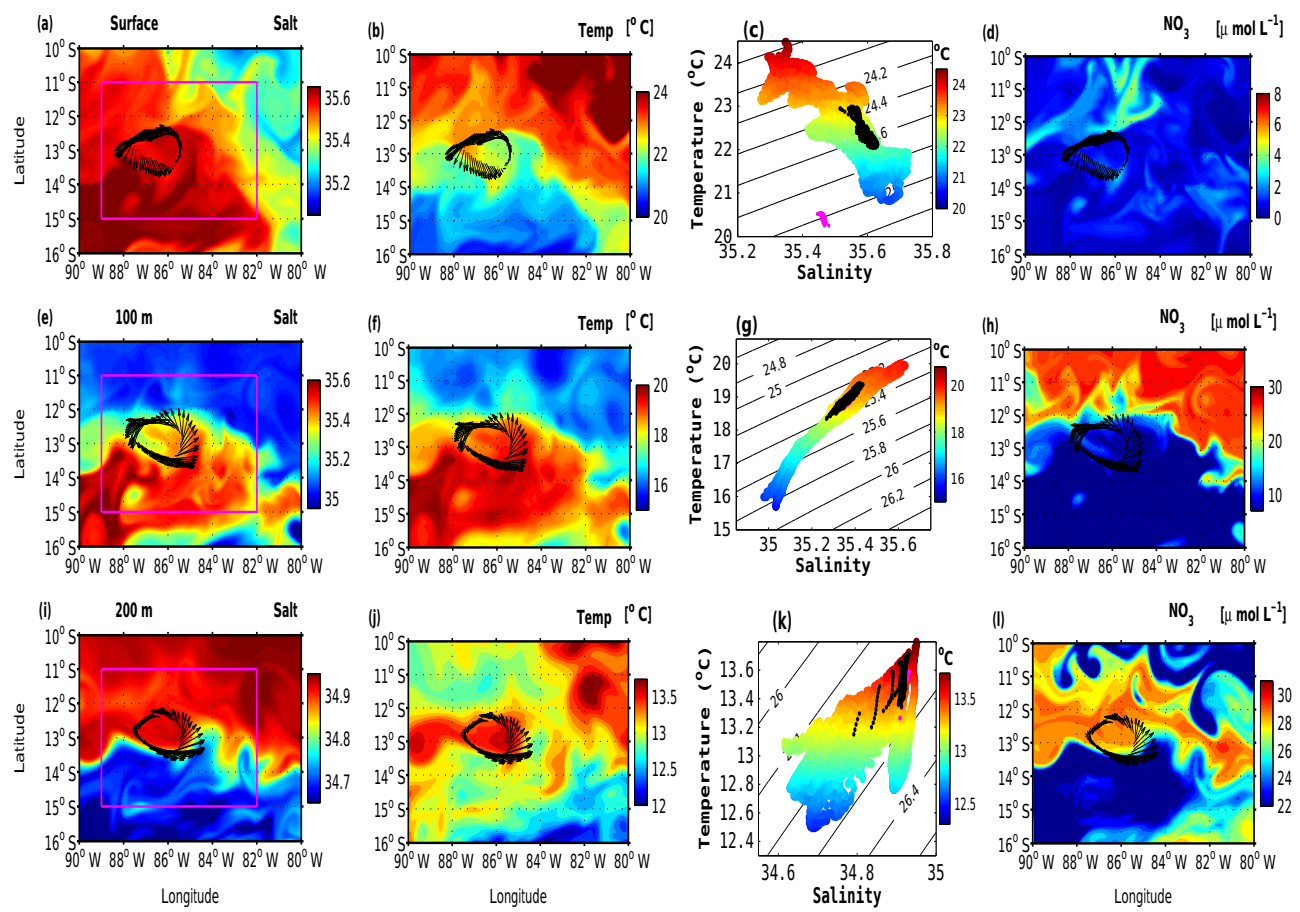

Figure 13. Water mass properties and nitrate distribution around the eddy $B_{\text {sim. }}$. Left panels: spatial distribution of simulated salinity at surface (top), $100 \mathrm{~m}$ (middle) and $200 \mathrm{~m}$ depth (bottom). Middle-left panels: the same as left panel, but for temperature. Middle-right panels: TS relation for surface (top), $100 \mathrm{~m}$ (middle) and $200 \mathrm{~m}$ depth (bottom) waters. Right panels: the same as left panel, but for nitrate. The arrows represent the circulation patterns at the eddy's edge. Black and magenta dots in the TS diagram correspond to the water masses within the eddy at the instant after the eddy formation (magenta) and the instant shown in Fig. 4 (black dots). The magenta box in Fig. 11a indicates the region over which the TS diagram is calculated.

water eddies (Thomsen et al., 2016). These mode-water anticyclonic eddies propagate westward and transport warm and salty equatorial subsurface in their centre (Chaigneau et al., 2011; Holte et al., 2013). Consequently, these mode-water eddies impact the water mass and biogeochemical property distributions of this region. Recent ship-based oceanographic measurements revealed the existence of diverse nutrient patterns within those eddies (Altabet et al., 2012; Stramma et al., 2013). A surprising finding was that, of two observed anticyclonic eddies, one had low nitrate concentrations and one had high nitrate concentrations at the subsurface layer (Stramma et al., 2013). The processes behind this diversity are discussed controversially. Altabet et al. (2012) and Stramma et al. (2013) suggest that nitrate consumption by denitrification is the cause of the low nitrate in one of the observed anticyclonic eddies. Their suggestion is supported by the high nitrite concentration measured within that eddy. In contrast, Thomsen et al. (2016) suggests that the low nitrate (high nitrite) water was entrained from the shelf region and trapped within the eddy structure rather than being produced locally by ongoing denitrification. For the high-nitrate eddy, Stramma et al. (2013) suggest the conditions at the eddy formation to play a significant role in the observed nutrient pattern. Using a coupled physical-biogeochemical model, we aim to understand the processes responsible for the different observed nutrient patterns within anticyclonic eddies off Peru. Our approach here is to assess local production and consumption rates relative to physical exchange of both nitrate and nitrite in the eddy interior with the environment outside the eddy. This is done for an extended period in two simulated anticyclonic eddies which feature nutrient patterns similar to the observed patterns. In the low-nitrate (high-nitrite) $A_{\text {sim }}$ eddy (Fig. 4c), the ongoing nitrate reduction by denitrification is lower than the nitrate production by nitrification. This fails to explain the low subsurface nitrate within the eddy, which is in contrast to the interpretation of the observations by Altabet et al. (2012) and Stramma et al. (2013). Further, in our simulation we find that the advective fluxes across the edge of the eddy $A_{\text {sim }}$ shows a strong nitrate supply into the eddy, in the first days prior to the eddy formation. This nitrate supply, which is predominately horizontal, is a consequence of the exchange of water masses with the surrounding environment during the eddy propagation. As for the nitrite dynamics, there is a nitrite supply into the eddy time subsequent to the eddy formation. This nitrite supply is higher than the biogeochemically produced concentrations. This result supports Thomsen et al. (2016), who suggest that the low-nitrate (high-nitrite) waters were entrained from the shelf region and trapped within the eddy interior. The analysis of water mass properties at three dif- 

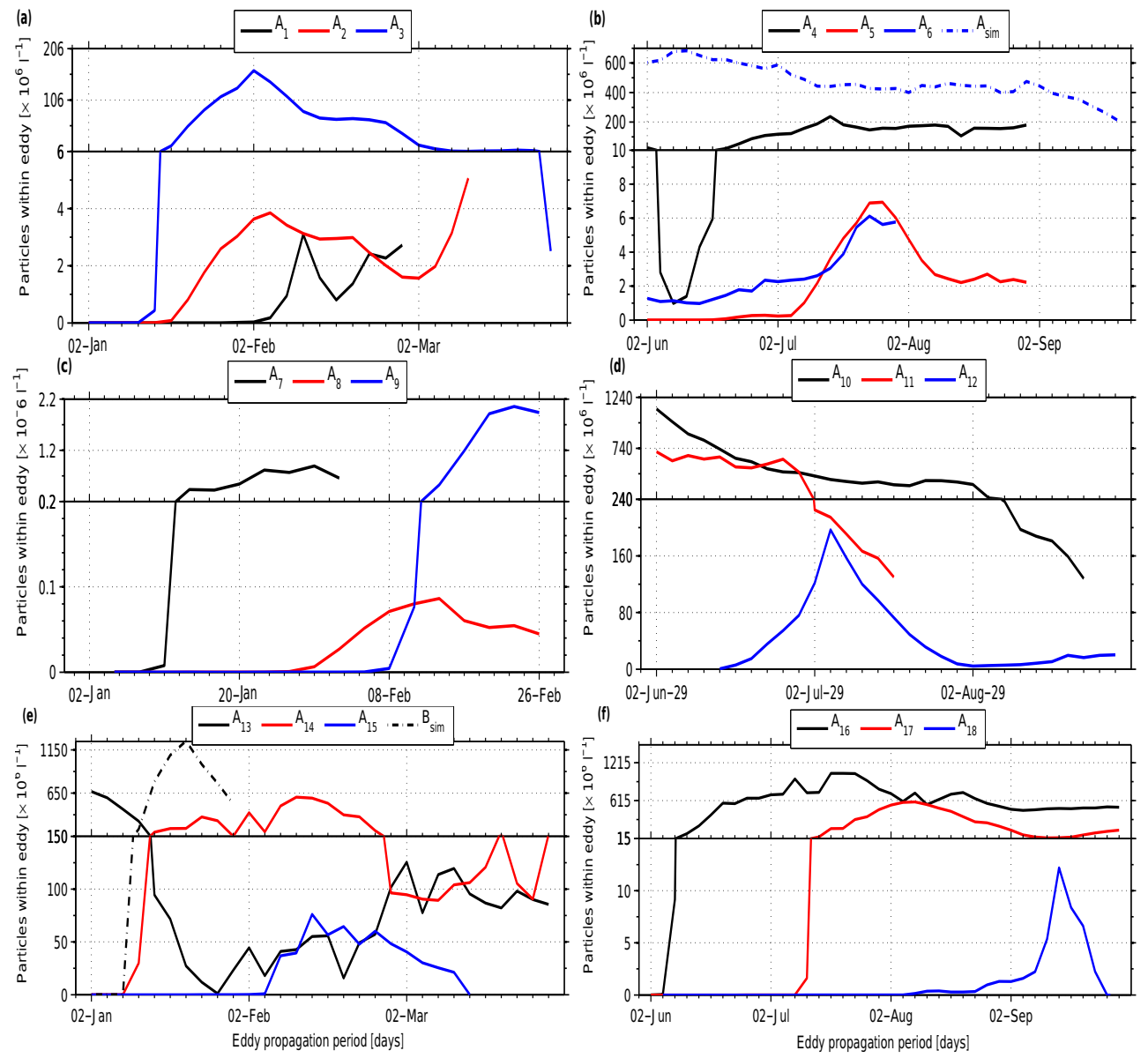

Figure 14. Particle distribution at the subsurface layer of anticyclonic eddies during their propagation, in summer (left) and winter (right) seasons. Anticyclonic eddies tracked at the vicinity of southern $(\mathbf{a}, \mathbf{b})$, northern $(\mathbf{c}, \mathbf{d})$ and offshore $(\mathbf{e}, \mathbf{f})$ particle-release locations. Detailed description of particle-release experiments is in the Supplement. Note the change of the scale on the vertical axes.

ferent layers of the eddy $A_{\text {sim }}$ 's interior shows a presence of water masses of different origin at different depths. At the surface, water masses are predominantly originating from the offshore region, characterized by relatively high temperatures and low-nitrate concentrations. The low-nitrate water at the subsurface layer originates from the shelf environment. These distinct water masses are trapped within the eddy structure. During the eddy propagation, there is an exchange of water masses with the surrounding environment, resulting in a reduction of temperature up to $4{ }^{\circ} \mathrm{C}$ from the eddy formation to the instant presented in Fig. 4. The dynamics within the high-nutrient eddy $B_{\text {sim }}$ (Fig. 5) also show exchange of water masses with the surrounding environment. The nitrate variation within the eddy appears to be related to the advective fluxes, which are an order of magnitude higher than the local production and consumption rates. The analysis of the nitrite dynamics within the eddy $B_{\text {sim }}$ shows some important aspects: (1) advective fluxes are of a similar magnitude to the biogeochemical fluxes, and (2) the nitrite availability outside the eddy is low during and after the eddy for- mation (Fig. S5 in the Supplement) and during its propagation (Fig. 13). These results suggest that the effect of biogeochemical processes on nutrient patterns within the eddy is important when the nutrient supply by physical processes is weak. However, the simulated local biogeochemical fluxes are not large enough (order of $1 \mathrm{nmolL}^{-1} \mathrm{~d}^{-1}$ ) to produce significant changes in nutrient concentrations. The nutrient fluxes into the eddy during its propagation depend on the nutrient concentrations in the environment surrounding the eddy. This argument also applies to eddy $A_{\text {sim }}$ : the nitriterich waters were entrained from the shelf and injected into the eddy $A_{\text {sim }}$ during its propagation. Anticyclonic eddies tracked during the particle-release experiments corroborate this suggestion and show the occurrence of water mass exchange between the eddy and the surrounding environment. Particle numbers within these eddies are repeatedly increased and decreased, showing a loss and gain of quantities to/from the surrounding environment. 


\section{Conclusions}

In this study we used simulated bio-physical dynamics to investigate the processes responsible for the observed diverse nutrient patterns within two anticyclonic eddies off Peru. Two anticyclonic eddies, based on their subsurface nitrate and nitrite patterns, were selected from the simulated dynamics and analysed. The model results show a decoupling between local nitrate reduction (nitrite production) via biogeochemical processes and total changes in nitrate (nitrite) within the eddy. Further, they indicate that the advection processes at the edge of the eddy play an important role in controlling the nutrient variability within the structure. In addition, the analysis of water mass properties show that the nutrient signature within the selected structures is related to the presence of water masses from different origins. In a more general context, the particle-release experiments realized in this study also enhance the role of water mass exchange between the eddies and the surroundings on setting the properties within the eddy structure. Our findings suggest that the biogeochemical patterns at the subsurface layer of the observed eddies in the ETSP are likely to be related to the presence of water masses from different origins, which are trapped and retained within the structure.

Data availability. Material is available under request to Y. S. José.

\section{The Supplement related to this article is available online at doi:10.5194/bg-14-1349-2017-supplement.}

Competing interests. The authors declare that they have no conflict of interest.

Acknowledgements. This work is financially supported by the Deutsche Forschungsgemeinschaft (DFG), under the Sonderforschungsbereich 754 "Climate-Biogeochemistry Interactions in the Tropical Ocean" project (http://www.sfb754.de). Simulations were performed using the computing facilities of the ChristianAlbrechts-Universität zu Kiel (NESH) and Norddeutscher Verbund zur Förderung des Hoch- und Höchstleistungsrechnens - HLRN. In situ circulation data were provided by the Instituto del Mar del Perú (IMARPE). We are grateful to A. Chaigneau for providing the in situ observations. Nutrient and oxygen in situ data were obtained from the German Collaborative Research Centre (SFB 754).

The article processing charges for this open-access publication were covered by a Research

Centre of the Helmholtz Association.

Edited by: L. Bopp

Reviewed by: three anonymous referees

\section{References}

Altabet, M. A., Ryabenko, E., Stramma, L., Wallace, D. W. R., Frank, M., Grasse, P., and Lavik, G.: An eddy-stimulated hotspot for fixed nitrogen-loss from the Peru oxygen minimum zone, Biogeosciences, 9, 4897-4908, doi:10.5194/bg-9-48972012, 2012.

Carton J. A. and Giese, B. S.: A Reanalysis of Ocean Climate Using Simple Ocean Data Assimilation (SODA), Am. Meteorol. Soc., 136, 2999-3017, doi:10.1175/2007MWR1978.1, 2008.

Chaigneau, A., Gizolme, A., and Grados, C.: Mesoscale eddies off Peru in altimeter records: Identification algorithms and eddy spatio-temporal patterns, Prog. Oceanogr., 79, 106-119, doi:10.1016/j.pocean.2008.10.013, 2008.

Chaigneau, A., Texier, M., Eldin, G., Grados, C., and Pizarro, O.: Vertical structure of mesoscale eddies in the eastern South Pacific Ocean: A composite analysis from altimetry and Argo profiling floats, J. Geophys. Res., 116, 1-16, doi:10.1029/2011JC007134, 2011.

Chaigneau, A., Dominguez, N., Eldin, G., Vasquez, L., Flores, R., Grados, C., and Echevin, V.: Near-coastal circulation in the Northern Humboldt Current System from shipboard ADCP data, J. Geophys. Res., 118, 1-16, doi:10.1002/jgrc.20328, 2013.

Chavez, F. P., Bertrand, A., Guevara-Carrasco, R., Soler, P., and Csirke, J.: The northern Humboldt Current System: Brief history, present status and a view towards the future, Prog. Oceanogr., 79, 95-105, doi:10.1016/j.pocean.2008.10.012, 2008.

Chelton, D. B., Schlax, M. G., Samelson, R. M., and de Szoeke, R. A.: Global observations of large oceanic eddies, Geophys. Res. Lett., 34, 1-5, doi:10.1029/2007GL030812, 2007.

Chelton, D. B., Gaube, P., Schlax, M. G., Early, J. J., and Samelson, R. M.: The Influence of Nonlinear Mesoscale Eddies on Near-Surface Oceanic Chlorophyll, Science, 334, 328-332, doi:10.1126/science.1208897, 2011a.

Cipollini, P., Cromwell, D., Challenor, P. G., and Raffaglio, S.: Rossby waves detected in global ocean colour data, Geophys. Res. Lett., 28, 323-326, 2001.

Codispoti, L. A. and Christensen, J. P.: Nitrification, denitrification and nitrous oxide cycling in the eastern tropical South Pacific Ocean, Mar. Chem., 16, 277-300, 1985.

Colas, F., McWilliams, J. C., Capet, X., and Kurian, J.: Heat balance and eddies in the Peru-Chile current system, Clim. Dynam., 39, 509-529, 2012.

Czeschel, R., Stramma, L., Schwarzkopf, F. U., Giese, B. S., Funk, A., and Karstensen, J.: Middepth circulation of the eastern tropical South Pacific and its link to the oxygen minimum zone, J. Geophys. Res., 116, 1-13, doi:10.1029/2010JC006565, 2011.

Czeschel, R., Stramma, L., Weller, R. A., and Fischer, T.: Circulation, eddies, oxygen, and nutrient changes in the eastern tropical South Pacific Ocean, Ocean Sci., 11, 455-470, doi:10.5194/os11-455-2015, 2015.

Debreu, L., Marchesiello, P., Penven, P., and Cambon, G.: Two-way nesting in split-explicit ocean models: algorithms, implementation and validation, Ocean Model., 49-50, 1-21, 2012.

Dietze, H., Matear, R., and Moore, T.: Nutrient supply to anticyclonic meso-scale eddies off western Austrailia estimated with artificial tracers released in a circulation model, Deep-Sea Res. Pt. I, 56, 1440-1448, doi:10.1016/j.dsr.2009.04.012, 2009. 
Falkowski, P., Ziemann, D., Kolber, Z., and Bienfang, P.: Role of eddy pumping in enhancing primary production in the ocean, $\mathrm{Na}$ ture, 352, 55-58, 1991.

Farías, L., Castro-González, M., Cornejo, M., Charpentier, J., Faúndez, J., Boontanon, N., and Yoshida, N.: Denitrification and nitrous oxide cycling within the upper oxycline of the eastern tropical South Pacific oxygen minimum zone, Limnol. Oceanogr., 54, 132-144, 2009.

Gutknecht, E., Dadou, I., Le Vu, B., Cambon, G., Sudre, J., Garçon, V., Machu, E., Rixen, T., Kock, A., Flohr, A., Paulmier, A., and Lavik, G.: Coupled physical/biogeochemical modeling including $\mathrm{O}_{2}$-dependent processes in the Eastern Boundary Upwelling Systems: application in the Benguela, Biogeosciences, 10, 35593591, doi:10.5194/bg-10-3559-2013, 2013.

Halo, I., Backeberg, B., Penven, P., Reason, C., Ansorge, I., and Ulgren, J.: Eddy properties in the Mozambique Channel: A comparison between satellite altimetry and Ocean Circulation models, Deep-Sea Res. Pt. II, 100, 119-135, doi:10.1016/j.dsr2.2013.10.015, 2014.

Hamersley, M. R., Lavik, G., Woebken, D., Rattray, J. E., Lam, P., Hopmans, E. C., Damste, J. S. S., Krüger, S., Graco, M., Gutiérrez, D., and Kuypers, M.: Anaerobic ammonium oxidation in the Peruvian oxygen minimum zone, Limnol. Oceanogr., 52, 923933, 2007

Holte, J., Straneo, F., Moffat, C., Weller, R., and Farrar, J. T.: Structure and surface properties of eddies in the southeast Pacific Ocean, J. Geophys. Res.-Oceans, 118, 119-135, doi:10.1002/jgrc.20175, 2013.

Hutchins, D. A., Hare, C. E., Weaver, R. S., Zhang, Y., Firme, G. F., DiTullio, G. R., Alm, M. B., Riseman, S. F., Maucher, J. M., Geesey, M. E., Trick, C. G., Smith, G. J., Rue, E. L., Conn, J., and Bruland, K. W.: Phytoplankton iron limitation in the Humboldt Current and Peru Upwelling, Limnol. Oceanogr., 47, 997-1011, 2002.

IOC, IHO and BODC: Centenary Edition of the GEBCO Digital Atlas, published on CD-ROM on behalf of the Intergovernmental Oceanographic Commission and the International Hydrographic Organization as part of the General Bathymetric Chart of the Oceans, British Oceanographic Data Centre, Liverpool, 2003.

Jenkins, W.: Nitrate flux into the euphotic zone near Bermuda, Nature, 331, 521-523, 1988.

José, Y. S., Aumont, O., Machu, E., Penven, P., Moloney, C. L., and Maury, O.: Influence of mesoscale eddies on biological production in the Mozambique Channel: Several contrasted examples from a coupled ocean-biogeochemistry Model, Deep-Sea Res. Pt. II, 100, 79-93, doi:10.1016/j.dsr2.2013.10.018, 2014.

Kalvelage, K., Lavik, G., Lam, P., Contreras, S., Arteaga, L., Löscher, C. R., Oschlies, A., Paulmier, A., Stramma, L., and Kuypers, M. M. M.: Nitrogen cycling driven by organic matter export in the South Pacific oxygen minimum zone, Nat. Geosci., 6, 228-234, doi:10.1038/NGEO1739, 2013.

Karstensen, J., Fiedler, B., Schütte, F., Brandt, P., Körtzinger, A., Fischer, G., Zantopp, R., Hahn, J., Visbeck, M., and Wallace, D.: Open ocean dead zones in the tropical North Atlantic Ocean, Biogeosciences, 12, 2597-2605, doi:10.5194/bg-12-2597-2015, 2015.

Lam, P., Lavik, G., Jensen, M. M., van de Vossenberg, J., Schmid, M., Woebken, D., Gutiérrez, D., Amann, R., Jetten, M. S. M., and Kuypers, M. M.: Revising the nitrogen cycle in the Peru- vian oxygen minimum zone, P. Natl. Acad. Sci., 106, 4752-4757, doi:10.1073/pnas.0812444106, 2009.

Lévy, M., Klein, P., and Treguier, A. M.: Impact of sub-mesoscale physics on production and subduction of phytoplankton in an oligotrophic regime, J. Mar. Res., 59, 535-565, 2001.

Liu, W. T., Tang, W., and Polito, P. S.: NASA scatterometer provides global ocean-surface wind fields with more structures than numerical weather prediction, Geophys. Res. Lett., 25, 761-764, 1998.

Mahadevan, A. and Archer, D.: Modelling the impact of fronts and mesoscale circulation on the nutrient supphy and biogeochemistry of the upper ocean, J. Geophys. Res., 105, 1209-1225, 2000.

Martin, A. and Richards, K.: Mechanism for vertical nutrient transport within a North Atlantic mesoscale eddy, Deep-Sea Res. Pt II, 48, 757-773, 2001.

Morel, A. and Berthon, J. F.: Surface pigments, algal biomass profiles, and potential production of the euphotic layer: Relationships reinvestigated in view of remote-sensing applications, Limnol. Oceanogr., 34, 1545-1562, 1989.

O'Reilly, J. E., Maritorena, S., Mitchell, B. G., Siegel, D. A., Carder, K. L., Garver, S. A., Kahru, M., and McClain, C.: Ocean color chlorophyll algorithms for SeaWiFS, J. Geophys. Res., 103, 24937-24953, 1998.

Ridgway, K. R., Dunn, J. R., and Wilkin, J. L.: Ocean interpolation by four-dimensional weighted least Squares-Application to the waters around Australasia, J. Atmos. Ocean. Tech., 19, 13571375, 2002.

Saraceno, M., Strub, P. T., and Kosro, P. M.: Estimates of sea surface height and near-surface alongshore coastal currents from combinations of altimeters and tide gauges, J. Geophys. Res., 113, 1-20, doi:10.1029/2008JC004756, 2008.

Shchepetkin, A. F. and McWilliams, J. C.: The regional oceanic modeling system (ROMS): a split-explicit, free-surface, topography-following-coordinate oceanic model, Ocean Model., 19, 347-404, 2005.

Smith, R. L.: Peru Coastal Currents During El Niño: 1976 and 1982, Science, 221, 1397-1399, doi:10.1126/science.221.4618.1397, 1983.

Stramma, L., Bange, H. W., Czeschel, R., Lorenzo, A., and Frank, M.: On the role of mesoscale eddies for the biological productivity and biogeochemistry in the eastern tropical Pacific Ocean off Peru, Biogeosciences, 10, 7293-7306, doi:10.5194/bg-10-72932013, 2013.

Stramma, L., Weller, R. A., Czeschel, R., and Bigorre, S.: Eddies and an extreme water mass anomaly observed in the eastern south Pacific at the Stratus mooring, J. Geophys. Res.-Oceans, 119, 1068-1083, doi:10.1002/2013JC009470, 2014.

Strub, T.: High-Resolution Ocean Topography Science Requirements for Coastal Studies, in: The Report of the High-resolution Ocean Topography Science Working Group meeting, edited by: Chelton, D. B., Ref. 2001-4, College of Oceanic and Atmospheric Sciences, Oregon State University, Corvallis, OR, 224 pp., 2001.

Thomsen, S., Kanzow, T., Krahmann, G., Greatbatch, R. J., Dengler, M., and Lavik, G.: The formation of a subsurface anticyclonic eddy in the Peru-Chile Undercurrent and its impact on the nearcoastal salinity, oxygen, and nutrient distributions, J. Geophys Res.-Oceans, 120, 476-501, doi:10.1002/2015JC010878, 2016. 
Ward, B. B., Devol, A. H., Rich, J. J., Chang, B. X., Bulow, S. E., Naik, H., Pratihary, A., and Jayakumar, A.: Denitrification as the dominant nitrogen loss process in the Arabian Sea, Nat. Lett., 461, 78-82, doi:10.1038/nature08276, 2009.

Worley, S. J., Woodruff, S. D., Reynolds, R. W., Lubker, S. J., and Lott, N.: ICOADS release 2.1 data and products, Int. J. Climatol., 25, 823-842, 2005.
Zibordi, G., Melín, F., and Berthon, J. F.: Comparison of SeaWiFS, MODIS and MERIS radiometric products at a coastal site, Geophys. Res. Lett., 33, 1-4, doi:10.1029/2006GL025778, 2006. 